•研究报告・

\title{
塔里木荒漠河岸林不同生境群落物种多度分布格局
}

\author{
康佳鹏@1, 韩路 ${ }^{2}$, 冯春晖 ${ }^{\circledR 2}$, 王海珍@2*
}

1. 塔里木大学生命科学学院, 新疆阿拉尔 $843300 ; 2$. 塔里木大学植物科学学院, 新疆阿拉尔 843300

摘要: 为解释塔里木荒漠河岸林群落构建和物种多度分布格局形成的机理, 本文以塔里木荒漠河岸林 2 个不同生境(沙地、河 漫滩) 4 ha固定监测样地为研究对象, 基于两样地物种调查数据, 采用统计模型(对数级数模型、对数正态模型、泊松对数正 态分布模型、Weibull分布模型)、生态位模型(生态位优先占领模型、断棍模型)和中性理论模型(复合群落零和多项式模型、 Volkov模型)拟合荒漠河岸林群落物种多度分布，并用K-S检验与赤池信息准则(AIC)䇥选最优拟合模型。结果表明: (1)随生境 恶化(土壤水分降低), 植物物种多度分布曲线变化减小, 群落物种多样性、多度和群落盖度降低, 常见种数减少。(2)选用的3 类模型均可拟合荒漠河岸林不同生境群落物种多度分布格局, 统计模型和中性理论模型拟合效果均优于生态位模型。复合群 落零和多项式模型对远离河岸的干旱沙地生境拟合效果最好; 对数正态模型和泊松对数正态模型对洪水漫溢的河漫滩生境 拟合效果最优; 中性理论模型与统计模型无显著差异。初步推断中性过程在荒漠河岸林群落构建中发挥着主导作用, 但模型 拟合结果只能作为推断群落构建过程的必要非充分条件，不能排除生态位过程的潜在作用。

关键词：荒漠河岸林; 生境; 物种多度分布; 模型拟合; 生态过程; 群落构建机制

康佳鹏, 韩路, 冯春晖, 王海珍 (2021) 塔里木荒漠河岸林不同生境群落物种多度分布格局. 生物多样性, 29, 875-886. doi: 10.17520/biods.2020416. Kang JP, Han L, Feng CH, Wang HZ (2021) Species abundance distribution in two riparian forests under contrasting environmental regimes in the Tarim Desert. Biodiversity Science, 29, 875-886. doi: 10.17520/biods.2020416.

\section{Species abundance distribution in two riparian forests under contrasting environmental regimes in the Tarim Desert}

\author{
Jiapeng Kang ${ }^{\circledR 1}$, Lu Han ${ }^{2}$, Chunhui Feng ${ }^{(\mathbb{D} 2}$, Haizhen Wang ${ }^{\left({ }^{2 *}\right.}$ \\ 1 College of Life Sciences, Tarim University, Alar, Xinjiang 843300 \\ 2 College of Plant Sciences, Tarim University, Alar, Xinjiang 843300
}

\begin{abstract}
Aims: Species coexistence mechanisms and species abundance distribution patterns at different time and spatial scales have been and may continue to be key issues in community ecology, whereas species abundance distribution is one of the most powerful tools for understanding the mechanisms generating community structures and biodiversity patterns. Studying species abundance distribution patterns in different habitats of forest communities can help to reveal the mechanisms that drive the formation and maintenance of biodiversity. This study took desert riparian forest communities as the research object, and analyzed the difference of species abundance distribution patterns in different habitats, in order to understand the dominant ecological processes of species abundance distribution and reveal assembly mechanism of desert riparian forest communities in extreme arid areas.

Methods: We surveyed two 4-ha desert riparian forests with contrasting inundation regimes and soil properties. We then employed four statistical models (i.e., log-series model, log-normal model, Poisson lognormal distribution model and Weibull distribution model), two niche-based models (i.e., niche preemption model, broken stick model) and two neutrally-based models (i.e., metacommunity zero-sum multinomial distribution model, Volkov model) to fit observed patterns of species abundance distributions for the two communities. We used the K-S test and Akaike information criterion (AIC) to select the best fitting model.
\end{abstract}

Results: Our results showed that: (1) The species composition and species abundance differed significantly between the

收稿日期: 2020-11-04; 接受日期: 2021-05-12

基金项目: 国家自然科学基金(31560182; 31860165; 31060066)和兵团区域创新引导计划(2018BB047)

* 通讯作者 Author for correspondence. E-mail: whzzky@163.com 
two desert riparian forest communities. In the less inundated and drier habitat, the species abundance distribution tended to have less interspecific variation, in addition to lower species diversity, abundance, forest cover, and fewer common species. (2) The statistical models and neutrally-based models performed better than the niche models in fitting species abundance distributions. The metacommunity zero-sum multinomial distribution model was the best-fitting model for the arid sandy habitat far from the river bank. The log-normal model and the Poisson lognormal model were the best-fitting models for the floodplain, whereas the neutral model (i.e., Volkov model) and the two aforementioned statistical models showed similar performance.

Conclusions: We therefore infer that a neutral process played a leading role in the assembly of the desert riparian forest communities. Since the species abundance distribution could be result of joint effect of multiple processes, we can not rule out the potential role of a niche-based process.

Key words: desert riparian forest; habitat; species abundance distribution; model fitting; ecological process; community assembly mechanism

多度一般指物种个体数量或种群密度, 或者说 是优势度和均匀度的度量指标, 反映了物种稀有度 或普遍度，揭示了一个物种占用资源的能力(任萍 等, 2009; 施建敏等, 2015)。物种多度分布(species abundance distribution, SAD) 是种间相互作用、环境 筛选与扩散限制等各种生态学过程共同作用的结 果, 能够反映群落内稀有种和常见种所占比例等群 落结构特征, 可用于推断群落构建的生态学过程, 被广泛应用于群落结构和生物多样性决定因素的 研究中 (McGill et al, 2007; 程佳佳等, 2011; Matthews \& Whittaker, 2015; 刘旻霞等, 2020)。

用数学方法结合生态学意义建立物种多度分 布模型来模拟物种多度分布的时空变化成为目前 多度分布格局研究的重要内容(Tokeshi, 1993)。自 Motomura (1932)首次利用几何级数模型(geommetric-series model)拟合湖泊底栖动物的物种多度分 布格局以来, 众多模型相继被建立。现有模型大致 可分为统计类模型与机理类模型两大类。统计类模 型是在统计假设下用数学方法推导出的物种多度 分布模型, 如对数级数模型(log-series model, Fisher et al, 1943)、对数正态模型 (log-normal model, Preston, 1948)、泊松对数正态分布模型(Poisson lognormal distribution model, Bulmer, 1974)、Weibull 分布模型(Weibull distribution model, 吴承祯和洪伟, 1997)。统计类模型可较好地对物种多度分布进行经 验拟合, 但其生态学意义不明确(MacArthur, 1957)。 机理类模型又分生态位模型与中性理论模型, 生态 位模型把物种多度与生态资源的占有或分配紧密 联系起来, 能推断物种多度分布的生态过程(李全 弟等, 2019), 如生态位优先占领模型 (niche preemption model, Whittaker, 1965)、断棍模型 (broken stick model, MacArthur, 1957)等。中性理论 模型认为群落中物种的竞争能力是等同的, 强调随 机过程在群落构建中起重要作用(Hubbell, 2005), 如复合群落零和多项式模型 (metacommunity zero-sum multinomial distribution model, Hubbell, 2001)、Volkov模型(Volkov model, Volkov et al, 2003)。目前, 有关物种多度分布的研究多数采用上 述两类模型拟合实验数据, 并推断群落构建机制 (McGill et al, 2007; 张姗等, 2015)。生态位过程和中 性过程是从两个不同的侧面来解释群落的物种多 度分布格局, 如何确定中性过程和生态位过程在群 落构建中的相对重要性是生态学研究的重要问题 (Wu et al, 2019)。

荒漠河岸林是西北干旱区宝贵的天然林，也是 荒漠地区生命现象最活跃、生物多样性和初级生产 力较高的独特生态系统 (Damasceno-Junior et al, 2005; Zhou et al, 2020)。塔里木盆地地处欧亚大陆腹 地, 远离海洋、气候干旱、降水稀少, 是以荒漠化 和盐渍化为基本特征的特殊生态环境，限制了森林 植被的分布和发展。贯穿盆地的塔里木河两岸分布 着适应荒漠河岸与扇缘带水分及盐化土壤的荒漠 植被, 并在高度异质性、多变地形、特殊土壤和水 盐条件下经长期自然演替形成了独特的荒漠河岸 林。近50年来，塔里木河流域大规模的水土资源开 发致使河流径流量日益减少、地下水位持续降低, 原有荒漠植被的生态过程与自然景观格局发生改 变, 植被退化、沙尘暴剧增、生物多样性锐减(陈亚 宁等, 2006), 严重危及荒漠绿洲生态服务功能与区 域社会经济的持续发展。研究表明，干旱荒漠区土 
壤水盐空间异质性是影响动植物生长及存活的主 要因子(Ulrich et al, 2016; Jiang et al, 2021), 不断恶 化的环境及种间对匮乏资源的激烈竞争限制了荒 漠植物的更新、扩散和生存(韩路等, 2016; 张雪妮 等, 2016)。

不同生境中决定群落格局的生态学过程可能 不同, 群落多样性格局与过程、物种丰富度与多度 分布格局也会随生境变化而变化(程佳佳等, 2011; 张雪妮等, 2016; 王健铭等, 2017; 李霞等, 2020)。王 健铭等(2017)发现西北荒漠区的植物物种丰富度格 局由生态位分化与中性过程以及其他未知因素共 同控制, 其中生态位分化的贡献可能更大; 张雪妮 等(2016)发现荒漠植物的多度分布在高水盐生境下 呈对数正态模型, 低水盐条件下符合Zipf模型, 多 度分布的变化反映了群落组成结构对水盐梯度的 响应。坤杜孜·萨塔尔等(2020)发现不同尺度下影响 荒漠物种多度分布格局的生态学过程基本一致, 初 步推断中性理论在荒漠植物群落物种多样性维持 过程中更为重要。

目前, 物种多样性格局相关研究主要针对森 林、草原等植被类型(Ulrich et al, 2016), 干旱区相关 研究集中于某一群落结构组成、丰富度与多样性梯 度格局及多度尺度效应等方面(张雪妮等, 2016; 王 健铭等, 2017; 坤杜孜·萨塔尔等, 2020), 对极端干 旱区荒漠河岸林不同生境物种多度分布格局的形 成机制关注较少, 尚不清楚荒漠河岸林物种多度分 布格局形成的原因, 以及环境篮选与扩散限制在荒 漠植物群落结构形成与生物多样性维持方面的相 对贡献, 对引起荒漠河岸林群落结构和物种组成变 化的生态过程缺乏足够了解。因此, 本文基于塔里 木荒漠河岸林 2 个不同生境的 4 ha固定样地的物种 多度数据, 选取 4 个统计模型、 2 个生态位模型、 2 个中性理论模型对荒漠河岸林物种多度曲线进行 拟合, 以期回答以下科学问题: (1)荒漠河岸林的物 种多度分布格局随生境的变化规律及差异; (2)主导 不同生境下荒漠河岸林物种多度分布的生态学过 程。以探讨不同生境物种多度分布格局背后的生态 学过程及其异同点, 揭示极端干旱区荒漠植物群落 构建机制, 为荒漠河岸林生态保育、植被恢复和生 物多样性维持提供科学参考。

\section{材料与方法}

\section{1 研究区概况}

研究区位于新疆塔里木河干流源头肖夹克(简 称塔河源, $\left.40^{\circ} 27^{\prime} \mathrm{N}, 80^{\circ} 56^{\prime} \mathrm{E}\right)$ 与沙雅县 $\left(40^{\circ} 41^{\prime} \mathrm{N}\right.$, $81^{\circ} 59^{\prime} \mathrm{E}$ )的两处天然胡杨(Populus euphratica)林 该 区域属暖温带极端大陆性干旱荒漠气候, 干燥多风 少雨, 年平均日照时数2,911.0 h, 太阳总辐射能 $5,796 \mathrm{MJ} \cdot \mathrm{m}^{-2} \cdot \mathrm{a}^{-1}$, 年平均气温 $10.7^{\circ} \mathrm{C}$, 极端最低 温度 $-28^{\circ} \mathrm{C}$, 极端最高温度 $40.6^{\circ} \mathrm{C}$, 平均气温 $\geq$ $10^{\circ} \mathrm{C}$ 的持续日数为 $201 \mathrm{~d}$, 光热同期。年降水不均, 蒸散强烈, 多年平均降水量 $50.4 \mathrm{~mm}$ 、平均蒸发量 $1,880.0 \mathrm{~mm}$ 。荒漠河岸林是塔里木极端干旱区内陆 河流域河流廊道植被类型的主体，其植被组成简单， 垂直结构层次分明, 物种多样性低, 植被稀疏。乔 木主要有胡杨、灰胡杨(Populus pruinosa); 灌木为 多枝柽柳(Tamarix ramosissima)、铃铛刺(Halimodendron halodendron)，黑果枸杞(Lycium ruthenicum); 草本主要有芦苇(Phragmites australis)、骆驼刺 (Alhagi sparsifolia)、甘草(Glycyrrhiza uralensis)、假 苇拂子茅(Calamagrostis pseudophragmites)、小花棘 豆(Oxytropis glabra)等。土壤类型为林灌草甸土。

\section{2 样地建立与群落调查}

经野外实地踏查, 于2019年6-8月分别在沙雅 县远离河岸的沙地生境(sandy habitat)与塔河源洪 水漫溢的河漫滩生境(floodplain habitat)各选择一块 林分整齐、人为干扰小、地势平坦, 具有代表性的 荒漠河岸林(图1), 按CTFS (Center for Tropical Forest Science)标准分别建立 $200 \mathrm{~m} \times 200 \mathrm{~m}$ 的固定 样地。将 2 个样地均划分为 16 个 $50 \mathrm{~m} \times 50 \mathrm{~m}$ 的样方, 采用相邻格子法, 以 $10 \mathrm{~m} \times 10 \mathrm{~m}$ 为基本单元对乔 木、灌木进行每木检尺, 记录胸径 $(\mathrm{DBH}) \geq 1.0 \mathrm{~cm}$ 的 全部乔木的种名、胸径、树高、冠幅等指标。因河 漫滩生境林下草本相对丰富, 在 $50 \mathrm{~m} \times 50 \mathrm{~m}$ 样方内 按“米”字型分别设置 9 个 $1 \mathrm{~m} \times 1 \mathrm{~m}$ 小样方, 对草本 植物种类、高度、盖度、多度等指标进行抽样调查, 并将其换算成 4 ha的总个体数。因沙地生境群落植 物种类少、分布稀疏、易于调查, 故 $200 \mathrm{~m} \times 200 \mathrm{~m}$ 样地内乔、灌、草皆采用每株检尺调查。按物种多 度由高到低进行优势度排序, 多度最多的优势度为 1 , 多度第二的优势度为 2 , 依此类推。同时, 参考 Hubbell和Foster (1986)的方法, 将每公顷密度 $\leq 1$ 
株的物种定义为稀有种, 1-10株为偶见种, 超过 100 株则为常见种。采用GPS定位记录各样方的经纬度、 海拔高度等生态因子。

\section{3 土壤采集与分析}

在沙地生境和河漫滩生境 $100 \mathrm{~m} \times 100 \mathrm{~m}$ 样方内 采用梅花取样法(5点)采集土样, 深度为 $1.0 \mathrm{~m}$, 分 5 层用土钻每隔 $20 \mathrm{~cm}$ 取土样, 5 个点的每层土进行混 样, 共5份。用铝盒和塑料袋封装, 带回实验室自然 风干, 研磨过篮后测定土壤 $\mathrm{pH}$ 值、电导率、质量含 水量、总盐、有机质、全氮、全磷、全钾、碱解氮、 有效磷、速效钾, 测定方法参考鲍士旦(2000), 运用 $t$ 检验对测定结果进行显著性分析。

\section{4 物种多样性指数}

采用 Patrick物种丰富度指数 $(S P)$ 、 Shannon-Wiener多样性指数 $\left(H^{\prime}\right)$ 、Pielou均匀度指数 $(E) 、$ Simpson优势度指数 $(D)$ 、Fisher指数 $(\alpha)$ 等测度 群落的物种多样性(Fisher et al, 1943; Hill, 1973; 陈 廷贵和张金屯, 1999), 其计算公式如下:

$$
\begin{aligned}
& S P=S \\
& H^{\prime}=-\sum P_{i} \ln P_{i} \\
& E=H^{\prime} / \ln S \\
& D=1-\sum P_{i}^{2}
\end{aligned}
$$

$$
\alpha=\ln (1+N / \alpha) / S
$$

式中, $S$ 为样方中物种数, $P_{i}$ 为第 $i$ 个种的重要值占总 重要值的比例。

\section{5 多度拟合模型选择}

由于自然群落复杂性及多种生物和环境因素 的影响, 单一模型无法对群落进行准确估计, 故本 文选择 4 个统计模型、2 个生态位模型、2个中性理 论模型对物种多度数据进行拟合, 并通过模型精度 检验确定最优模型。

\subsection{1 统计模型}

(1)对数级数模型。对数级数分布是负二项分布 在 $k=0$ 时的特殊情况, 不考虑个体数为 0 的种 (Fisher et al, 1943)。根据本模型, 群落内多度为 $n$ 的 物种数 $S$ 可表示为:

$$
S(n)=\alpha \frac{X^{n}}{n}
$$

式中, 作为群落的物种多样性指数, $\alpha>0$ 且与样本 大小无关, $X$ 为常数 $(0<X \leq 1)$, 受样本大小影响。

(2)对数正态模型。Preston (1948)最早用其进行 多度分布研究, 该模型认为群落内物种个体数的对 数符合正态分布。对于物种多度分布来说, 变量为 每个物种所具有的个体数, 因子即影响群落组成的 各种过程。 


$$
A_{i}=e^{\log (\mu)+\log (\delta) \Phi}(i=1,2,3, \ldots, S)
$$

式中, $\mu$ 为正态分布的均值, $\delta$ 为方差, $\Phi$ 为正态偏差, $A_{i}$ 为第 $i$ 个物种的多度。

(3)泊松对数正态分布模型。Bulmer (1974)提出 用泊松对数正态分布拟合观察数据, 假设第 $j$ 种的 个体数是 $\lambda_{j}$ 的一个泊松变量, 将 $j=1,2, \ldots, S^{*}$ 的 $\lambda_{j}$ 值 看作对数正态分布的 $S^{*}$ 个独立观察, 样本中 1 个种 包含 $r$ 个个体的概率为:

$$
p_{r}=\int_{0}^{\infty}\left[\frac{\lambda^{r} e^{-\lambda}}{r !}\right]\left\{\frac{1}{\lambda^{e} \overline{2}^{c}} \exp \left[-\frac{1}{2^{e^{2}}}\left[\ln \frac{\lambda}{m}\right]^{2}\right]\right\} d \lambda
$$

式中, $r=0,1,2, \ldots, \lambda>0$ 。这个概率取决于两个参 数 $\sigma 、 m, \sigma$ 与样本大小无关, $m$ 为中位多度, 是样本大 小的函数。

(4) Weibull分布模型。吴承祯和洪伟(1997)利用 形状参数 $c$ 作为反映群落物种多度特征的指标, 将 Weibull分布模型用于拟合万木林自然保护区观光 木(Tsoongiodendron odorum)群落的物种多度分布。

$$
f(x)=\frac{c}{b}(x-a)^{c-1} \exp \left(-\frac{(x-a)^{c}}{b}\right)
$$

式中, $x \geq a ; a>0$, 为位置参数, 由于物种多度最小 可以理解为 0 , 故 $a$ 可取介于 $0-1$ 之间的任意值; $b>0$, 为尺度参数; $c>0$, 为形状参数。

\subsection{2 生态位模型}

(1)生态位优先占领模型。Whittaker (1965)假定 第一个物种先占用群落总生态位的 $k$ 份, 第二个物 种占用剩余的 $k(1-k)$ 份, 第三个种再占用剩余的 $k(1-k)^{2}$ 份, 依此类推。当物种以相同的时间间隔进 入不饱和的生境, 并且占据生态位的一部分时, 就 会形成生态位优先占领模型的分布模式。模型中优 势度最高物种的多度表示为 $N_{1}$, 则第 $\mathrm{i}$ 个物种的多度 $N_{i}$ 可以表示为:

$$
N_{\mathrm{i}}=N_{1}(1-k)^{i-1} \quad(i=1,23, \ldots)
$$

(2)断棍模型。由MacArthur (1957)提出, 是一种 资源分配模型。该模型假定一个群落中的总生态位 (资源总量)是等于 1 的一条断棍, 在棍上随机设 $S-1$ 个点, 把断棍分割为 $S$ 段, 代表生态位被 $S$ 个物种占 有。模型假定 $S$ 个物种的分类地位和竞争能力均相 似, 而且同时在群落中出现。以 $J$ 表示群落中物种的 个体总数, 则可将第 $i$ 个物种的多度 $A_{i}$ 表示为:

$$
A_{i}=\frac{J}{S} \sum_{x=i}^{S} \frac{1}{x} \quad(i=1,2,3 \ldots)
$$

\subsection{3 中性理论模型}

(1)复合群落零和多项式模型。该模型假定任意 取样点的物种多度分布是中性复合群落在随机生 态漂变作用下的产物(Hubbell, 2001), 包括两个参 数: 取样点物种的个体数 $(J)$ 和基本多样性指数 $(\theta)$ 。 在一个群落中, 任意一个个体死亡后, 它被一个新 物种取代的概率是 $v$, 而被任意一个余下个体的后 代取代的概率是 $1-v$, 则 $\theta=2 J v$ 。由于取样点的物 种个体数 $J$ 是确定的, 因此该模型只包含一个不确 定参数 $\theta$ (张姗等, 2015)。该模型认为复合群落中, 任意取样点内多度为 $n$ 的物种数量 $S$ 为:

$$
\begin{aligned}
& S(n)=\frac{\theta}{n} \int_{0}^{J} f_{n .1}(y)\left(1-\frac{n}{J}\right)^{\theta-1} d y \\
& f_{n, \delta}(y)=\frac{1}{\Gamma(n) \delta^{n}} \exp \left(-\frac{y}{\delta}\right) y^{n-1} \\
& \Gamma(\mathrm{z})=\int_{0}^{\infty} t^{z-1} e^{-t} d t
\end{aligned}
$$

(2) Volkov模型。该模型在复合群落零和多项 式模型的基础上增加了参数迁移系数 $m$, 并假设物 种从复合群落到局域群落的迁移系数 $m$ 是固定不变 的, 局域群落中多度为 $n$ 的物种数量 $S$ 可表示为:

$$
\begin{aligned}
& S(n)=\theta \frac{J !}{n !(J-n) !} \frac{\Gamma(\gamma)}{\Gamma(J+\gamma)} \int_{0}^{\gamma} \frac{\Gamma(n+y)}{\Gamma(1+y)} \\
& \frac{\Gamma(J-n+\gamma-y)}{\Gamma(\gamma-y)} \exp \left(-\frac{y \theta}{\gamma}\right) d y \\
& \Gamma(\mathrm{z})=\int_{0}^{\infty} t^{z-1} e^{-t} d t \\
& \gamma=\frac{m(J-1)}{1-m}
\end{aligned}
$$

式中, $J$ 为群落样本大小, $\Gamma(\mathrm{z})$ 为 $z$ 的函数, $\gamma$ 为迁移到 局域群落的个体数(Volkov et al, 2003)。

\section{6 模型拟合效果检验}

\subsubsection{K-S检验}

采用Kolmogorov-Smirnov (K-S)检验模型拟合 结果与实际观测分布的差异。K-S检验是一种非参 数检验方法, 通过计算两个样本的经验分布函数 
(empirical distribution function)之间的距离(统计量 $D)$ 来判断二者是否存在显著差异, 若 $P<0.05$, 则 表示该模型被拒绝(方晓峰等, 2016)。

\subsubsection{AIC准则}

采用AIC (Akaike information criterion)评估模 型拟合的优劣性。在模型选择时, 含有的参数越少, 概率密度分布与真实数据越接近, AIC值越小, 模 型拟合效果最优。其定义为:

$$
\text { AIC }=-2 \ln (L)+2 k
$$

式中, $L$ 代表所使用模型极大似然函数的估计值, $k$ 代表模型中出现的参数个数(Burnham \& Anderson, 2002)。根据Burnham和Anderson (2002)的建议，一 般认为模型之间 AIC值的差异大于 2 时, 两个模型 有显著差异。

\section{7 数据处理}

将物种的多度以 2 为底进行对数转换, 并合并 相邻多度区间进行分组, 按物种多度值的高低进行 排序作图，以此得到相应的物种多度直方图。

文中所有的数据整理采用Excel 2019完成, 数 据统计分析、模型拟合及检验均采用R 3.6.2中的软 件包sads (Prado et al, 2018)完成; 利用Origin 2018 作图。

\section{2 结果}

\section{1 荒漠河岸林不同生境的土壤因子差异}

采用 $t$ 检验发现不同生境的土壤特征存在差异, 河漫滩生境的土壤质量含水量、土壤 $\mathrm{pH}$ 值均极显著
高于沙地生境 $(P<0.01)$ (表1), 说明近河岸的河漫 滩生境有较好的水分条件; 两生境土壤营养元素 (氮、磷、钾)均无显著差异 $(P>0.05)$ 。

\section{2 荒漠河岸林物种多度分布}

塔里木荒漠河岸林沙地生境共调查到4科5属5 种(图2), 稀有种、偶见种、常见种的种数相似, 其 中稀有种西北天门冬(Asparagus persicus)仅发现1 株，常见种胡杨多度最大。河漫滩生境共调查到 9 科11属11种(图2), 稀有种未见，常见种与偶见种的 种数差异明显，物种多度直方图呈正态分布。

由荒漠河岸林 2 个生境的物种累积经验分布曲 线(empirical cumulative distribution function, ECDF) 可知(图3), 两生境的ECDF呈现不同程度的S型, 且 $\mathrm{K}-\mathrm{S}$ 结果显示两生境ECDF之间存在显著差异 $(D=$ $0.73, P=0.029$ )。

\section{3 不同生境物种多度分布曲线}

运用 4 个统计模型、 2 个生态位模型和 2 个中性 理论模型对荒漠河岸林不同生境的物种多度进行 拟合(表2), 不同生境K-S检验结果显示，8种模型均 未被拒绝 $(P>0.05) 。 \mathrm{AIC}$ 检验结果显示(表2), 沙地 生境模型拟合的优度依次为复合群落零和多项式 模型 > 对数级数模型 > Volkov模型 $>$ Weibull分 布模型 $>$ 泊松对数正态分布模型 $>$ 对数正态模 型 > 断棍模型 > 生态位优先占领模型, 复合群落 零和多项式模型为最优模型。河漫滩生境模型拟合 的优度依次为对数正态模型 $=$ 泊松对数正态分布 模型 > Volkov模型 > Weibull分布模型 $>$ 复合群

\section{表1 荒漠河岸林不同生境的土壤特征(平均值 \pm 标准差)}

Table 1 Soil characteristics of two different habitats in desert riparian forest (mean \pm SD)

\begin{tabular}{lllll}
\hline & 沙地生境 Sandy habitat & 河漫滩生境 Floodplain habitat & $P$ & $t$ \\
\hline 土壤质量含水率 Soil mass water content $(\%)$ & $0.62 \pm 0.11^{\mathrm{A}}$ & $21.95 \pm 1.23^{\mathrm{B}}$ & $<0.01$ & 2.01 \\
电导率 Electrical conductivity $(\mu \mathrm{S} / \mathrm{cm})$ & $1,819.87 \pm 272.90^{\mathrm{a}}$ & $1,105.93 \pm 293.60^{\mathrm{a}}$ & 0.09 & 2.05 \\
$\mathrm{pH}$ & $8.02 \pm 0.03^{\mathrm{A}}$ & $8.20 \pm 0.03^{\mathrm{B}}$ & $<0.01$ & 2.05 \\
土壤有机质 Soil organic matter (g/kg) & $2.48 \pm 0.30^{\mathrm{a}}$ & $2.74 \pm 0.73^{\mathrm{a}}$ & 0.96 & 2.12 \\
全氮 Total nitrogen (g/kg) & $0.18 \pm 0.03^{\mathrm{a}}$ & $0.22 \pm 0.05^{\mathrm{a}}$ & 0.68 & 2.14 \\
全磷 Total phosphorus (g/kg) & $7.22 \pm 0.50^{\mathrm{a}}$ & $7.43 \pm 0.38^{\mathrm{a}}$ & 0.97 & 2.20 \\
碱解氮 Available nitrogen (mg/kg) & $6.46 \pm 2.74^{\mathrm{a}}$ & $6.95 \pm 1.06^{\mathrm{a}}$ & 0.30 & 2.20 \\
有效磷 Available phosphorus (mg/kg) & $105.40 \pm 15.07^{\mathrm{a}}$ & $109.62 \pm 6.30^{\mathrm{a}}$ & 0.68 & 2.12 \\
速效钾 Available potassium (mg/kg) & $203.56 \pm 32.83^{\mathrm{a}}$ & $180.69 \pm 34.23^{\mathrm{a}}$ & 0.54 & 2.12
\end{tabular}

同一行不同大写字母表示差异极显著 $(P<0.01)$, 不同小写字母表示差异显著 $(P<0.05)$ 。

Different capital letters on the same line denoted extremely significant difference $(P<0.01)$, different lowercase letters denoted significant difference $(P<0.05)$. 

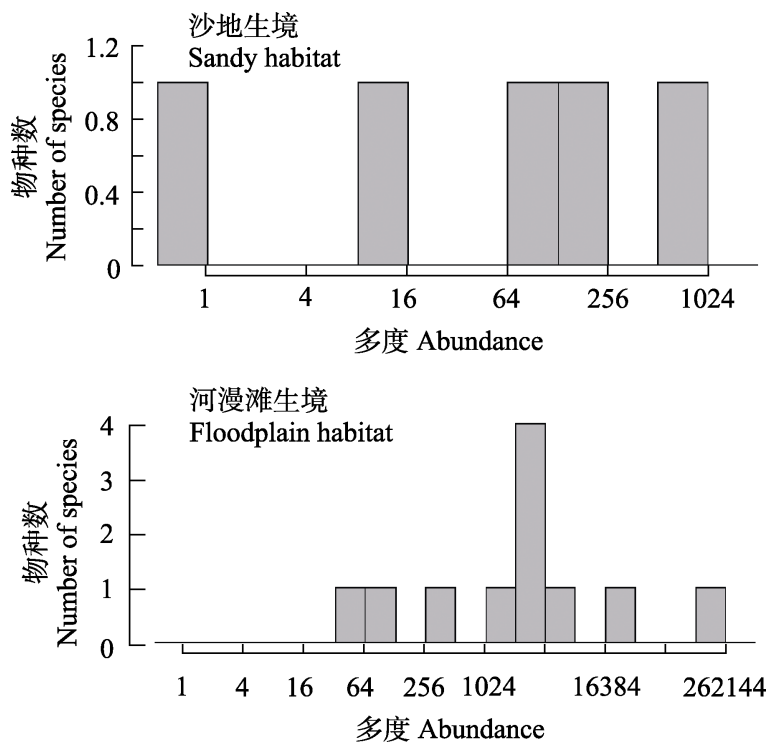

图2 荒漠河岸林不同生境物种多度直方图

Fig. 2 Species abundance diagram at different habitats in desert riparian forest

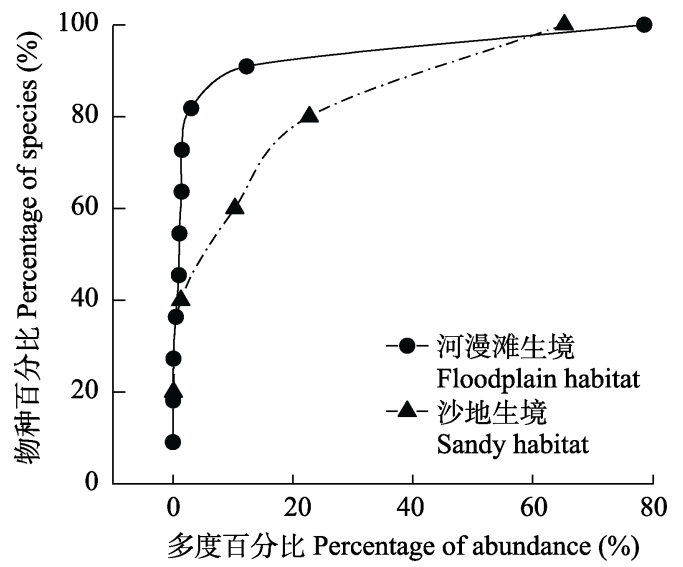

图3 荒漠河岸林不同生境物种的累积经验分布函数

Fig. 3 The empirical cumulative distribution function of species at different habitats in desert riparian forest
落零和多项式模型 $>$ 对数级数模型 $>$ 生态位优先 占领模型 > 断棍模型, 统计模型中的对数正态模 型、泊松对数正态分布模型为最优模型。

沙地生境中复合群落零和多项式模型与对数 级数模型、Volkov模型AIC值的差值 $<2$, 河漫滩生 境对数正态模型、泊松对数正态分布模型与Volkov 模型、Weibull分布模型AIC值的差值 $<2$, 可认为 上述模型间无显著差异, 皆可较好地拟合物种多度 分布。群落物种多度拟合结果也证实(图4), 统计模 型与中性理论模型的拟合结果与实际观测数据较 为吻合, 而生态位模型对 2 个不同生境物种多度分 布的拟合结果则一般。此外, 从 8 个模型拟合曲线来 看, 沙地生境曲线斜率明显小于河漫滩生境, 表明 沙地生境各物种相对多度差异较小, 物种丰富度与 多样性较低, 这与实际调查结果一致。

荒漠河岸林不同生境物种组成与多度差异明 显，随生境恶化物种数与多度均明显降低。在中性 理论模型参数中, 河漫滩生境复合群落零和多项式 模型的基本多样性指数 $(\theta=11)$ 与Volkov模型的迁 移率 $(m=0.39)$ 皆高于沙地生境 $(\theta=5, m=0.01)$ 。河 漫滩生境的Shannon-Wiener多样性指数、Simpson 多样性指数、Pielou均匀度指数、Fisher- $\alpha$ 指数均高 于沙地生境(图5)。

\section{3 讨论}

\section{1 荒漠河岸林群落多度分布格局模型的选取}

研究物种的多度分布格局常使用数学和生态 学相结合的方法, 通过建立数学模型来拟合多度分 布格局的时空变化, 而不同生态学模型可反映出主

表2 荒漠河岸林不同生境物种多度分布模型的拟合优度检验

Table 2 Goodness of fit test of species abundance distribution models at different habitats in desert riparian forest

\begin{tabular}{|c|c|c|c|c|c|c|c|}
\hline \multirow{2}{*}{$\begin{array}{l}\text { 模型类型 } \\
\text { Model type }\end{array}$} & \multirow{2}{*}{$\begin{array}{l}\text { 模型名称 } \\
\text { Model name }\end{array}$} & \multicolumn{3}{|c|}{ 沙地生境 Sandy habitat } & \multicolumn{3}{|c|}{ 河漫滩生境 Floodplain habitat } \\
\hline & & $\overline{\mathrm{AIC}}$ & $D$ & $P$ & $\overline{\mathrm{AIC}}$ & $D$ & $P$ \\
\hline \multirow{4}{*}{$\begin{array}{l}\text { 统计模型 } \\
\text { Statistical model }\end{array}$} & 对数级数模型 Log-series model & 59.80 & 0.20 & 1.00 & 227.10 & 0.36 & 0.46 \\
\hline & 对数正态模型 Log-normal model & 63.08 & 0.20 & 1.00 & 220.80 & 0.18 & 1.00 \\
\hline & 泊松对数正态分布模型 Poisson lognormal distribution model & 62.82 & 0.20 & 1.00 & 220.80 & 0.18 & 1.00 \\
\hline & Weibull分布模型 Weibull distribution model & 62.57 & 0.20 & 1.00 & 222.70 & 0.18 & 1.00 \\
\hline \multirow{2}{*}{$\begin{array}{l}\text { 生态位模型 } \\
\text { Niche model }\end{array}$} & 断棍模型 Broken stick model & 63.31 & 0.40 & 0.87 & 251.40 & 0.55 & 0.07 \\
\hline & 生态位优先占领模型 Niche preemption model & 63.95 & 0.40 & 0.87 & 241.50 & 0.55 & 0.07 \\
\hline \multirow{2}{*}{$\begin{array}{l}\text { 中性理论模型 } \\
\text { Neutral theory } \\
\text { model }\end{array}$} & 复合群落零和多项式模型 & 58.70 & 0.20 & 1.00 & 226.10 & 0.36 & 0.48 \\
\hline & $\begin{array}{l}\text { Metacommunity zero-sum multinomial distribution model } \\
\text { Volkov模型 Volkov model }\end{array}$ & 60.44 & 0.20 & 1.00 & 222.50 & 0.18 & 1.00 \\
\hline
\end{tabular}

AIC: 赤池信息准则, $D$ : K-S检验统计量。AIC, Akaike information criterion. $D$, Statistic of K-S test. 

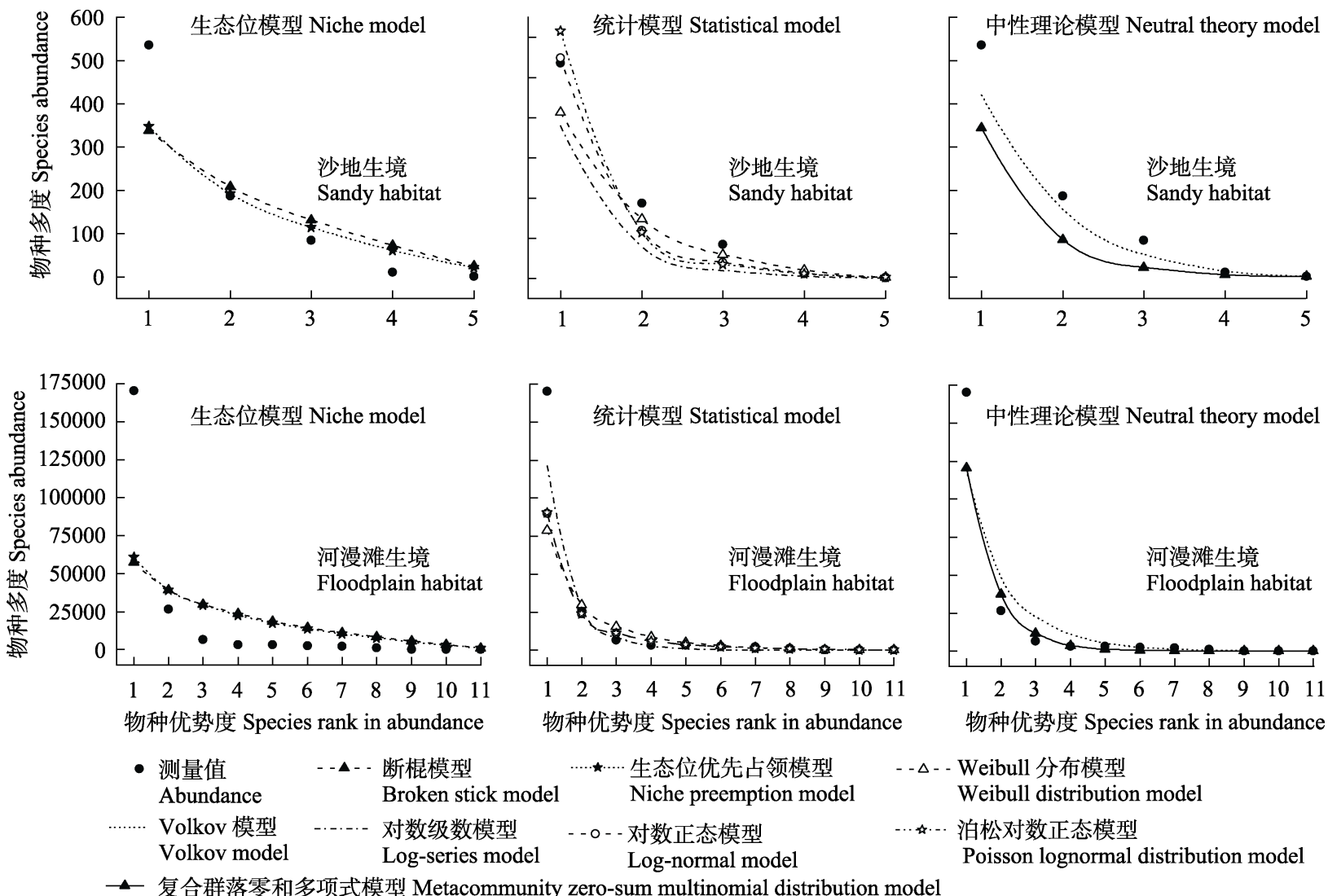

- - - - - Weibull 分布模型

Weibull distribution model

……泊松对数正态模型

Poisson lognormal distribution model

图4 荒漠河岸林不同生境物种多度分布及模型拟合

Fig. 4 Species abundance distribution and model fitting at different habitats in desert riparian forest

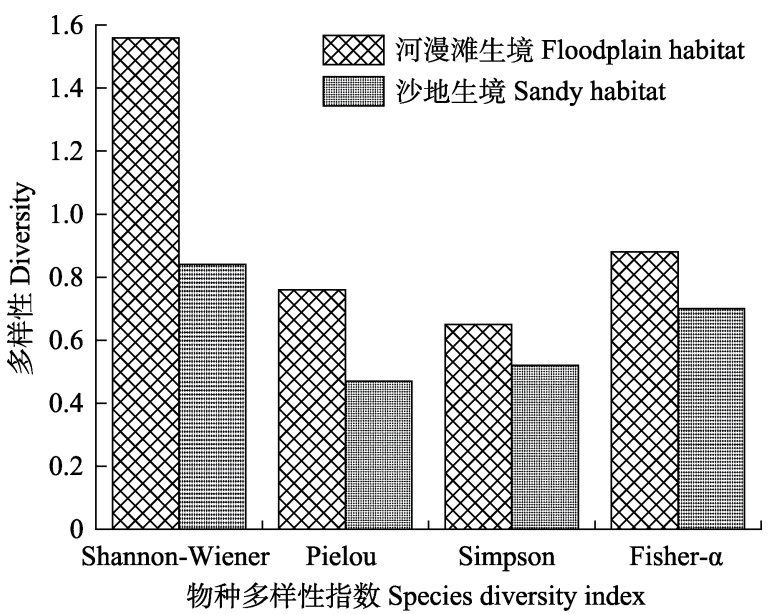

图5 荒漠河岸林不同生境植物的物种多样性

Fig. 5 Difference of plant diversity of species at different habitats in desert riparian forest

导群落物种分布格局的生态学过程和机制(闵琰等, 2012; 张姗等, 2015; 李全弟等, 2019)。本文选取3 类8个模型对不同生境的荒漠河岸林群落多度分布 格局进行拟合, 发现统计模型和中性理论模型的拟 合效果均优于生态位模型。其中统计模型中对数正
态模型、泊松对数正态分布模型对塔河源河漫滩生 境的拟合效果最好，同时最优模型与Weibull分布模 型、中性理论模型的Volkov模型拟合结果无显著差 异(AIC差值 < 2)。原因可能是统计模型在统计假设 下通过对实测数据进行数学方法推导得出物种分 布模型，而中性理论模型中的生态位等价假设、群 落的饱和性假设都认为群落中物种个体总数量是 相对固定的，受扩散限制等随机过程决定(Hubbell, 2001)。生态位模型将群落中的总生态位假设为1, 进行多度分布拟合，这与真实情况并不相符，因而 拟合结果没有统计模型好。但统计模型描述的是物 种多度分布格局及其数量间的关系(Wu et al, 2019), 相比之下中性理论模型更易于阐释群落物种多度 分布格局的形成机制(Volkov et al, 2003)。中性理论 模型的复合群落零和多项式、Volkov模型及对数级 数模型对沙地生境拟合效果较好。Hubbell (2001) 指出统计模型中的对数级数模型是复合群落零和 多项式模型(中性理论模型)的一个特例，二者的拟 合效果是相似的(方晓峰等, 2016)。可见，虽然荒漠 
河岸林不同生境的群落物种多度分布格局存在显 著差异, 但模型拟合的结果近似相同。因此, 初步 认为中性过程是主导荒漠河岸林群落物种多样性 形成的主要机制。

\section{2 不同生境荒漠河岸林群落多度分布格局形成 的生态学过程}

塔里木荒漠河岸林群落物种组成、物种多样性 和物种多度分布格局随生境干旱程度发生了明显 的变化, 导致与其符合的多度分布模型也随之改变 (表2, 图4)。但本研究发现主导不同生境物种多度分 布格局形成的生态学过程相似, 即中性过程。分析 其可能的原因有以下两个方面: 首先, 从河漫滩生 境到沙地生境, 土壤养分含量与土壤含水量降低 $(P$ $<0.01)$, 物种丰富度与生物多样性指数也随之下 降。在严酷生境下, 以生态位为基础的环境篎选、 生态位分化常常被认为是群落构建的主导过程(施 建敏等, 2015; 刘旻霞等, 2020), 以致扩散限制的作 用易被忽略(王世雄等, 2013); 且生态学家发现, 将 具有不同生态特性(如个体大小、扩散能力等)的物 种合并考虑时, 可能会造成某些格局(如物种多度 分布)潜在的特殊性被掩盖或某些信息的丢失 (Magurran \& Henderson,2003; Matthews \& Whittaker, 2015)。沙地生境常年干旱缺水, 限制了物种生长发 育与迁移, 降低了物种迁移率; 且物种主要以无性 繁殖(根藥)扩张, 扩展范围较窄, 呈现斑块状分布, 物种为了生存、协同抵御严酷生境而趋向互利(韩路 等, 2007), 种间竞争较弱; 或物种对干旱环境的适 应能力大致相似, 各自占据着所需生态位而形成稳 定共存格局, 导致生态位过程减弱(Laurance et al, 1998; 程佳佳等, 2011), 中性过程增强。

河漫滩生境常年受塔里木河河水补给, 土壤水 分充足, 优越的环境资源维持着相对较高的群落物 种多样性与多度; 但乔灌木种类少、密度低、个体 间距离较大, 不同物种能有效地获取较为充分的生 存资源, 生境过滤(如干旱胁迫等)和种间作用并不 强烈, 物种间的生态位分化作用可能较弱(刘加珍 等, 2004), 这可能会降低生态位过程的作用(方晓峰 等, 2016)。每年7-9月季节性汛期产生洪水漫溢, 洪 水干扰作为生境过滤因素会降低群落内的种间竞 争作用, 导致生态位过程对群落物种多度分布格局 的贡献减弱 (Mayfield \& Levine, 2010; 间琰等, 2012); 且洪水携带周边区域植物种子在此定植(韩
路等, 2019), 增强物种的扩散。

其次, 扩散限制不仅依赖于物种本身的性状, 也依赖于生境破碎化程度与群落的斑块状分布, 生 境破碎化与群落斑块状分布可以在局域尺度上明 显减小区域上物种的拓殖过程(Fralish et al, 1991)。 从生境优越的河漫滩向沙地生境变化过程中, 单一 物种多度与总物种多度皆随生境恶化(土壤水分减 少)而降低, 尤其是常见种数(灌、草)和优势种多度 显著减少; 同时物种均匀度、群落物种多度分布曲 线斜率与迁移率均减小, 表明随土壤干旱沙化贫癐, 物种定植环境差, 群落中物种的结实率与传播者的 多度及其拓殖过程减弱。因此, 扩散限制(中性过程) 成为塔里木荒漠河岸林不同生境群落物种多度分 布、群落构建的主导作用。

\section{3 物种多度分布格局对荒漠河岸林群落构建过程 的检验}

生态学格局与过程往往不是一一对应关系, 相 同的格局可能是由不同的生态学过程导致的 (Mayfield \& Levine, 2010; 方晓峰等, 2016; 王健铭 等, 2017; Jiang et al, 2021)。因此, 物种多度分布格 局是阐释群落构建机制的必要非充分条件(McGill et al, 2007; 牛克昌等, 2009)。大量研究证明中性理 论与生态位理论并非是相互排斥的, 任一群落都可 在“纯生态位过程到纯中性过程连续体” 上找到对应 的位置, 二者共同对群落构建过程起作用(闰琰等, 2012; 张姗等, 2015; 李全弟等, 2019)。

本研究通过拟合优度检验结果发现, 3类8个模 型均能够拟合荒漠河岸林不同生境群落物种多度 分布, 统计模型和中性理论模型的拟合效果优于生 态位模型, 表明出现了确定性和随机性可以共存的 现象, 即自然群落不具有单纯的确定性和随机性, 而是这两种现象的有机结合体(刘梦雪等, 2010)。方 晓峰等(2016)认为中性过程与生态位过程对群落物 种构建的作用可能呈此消彼长状态, 当生态位过程 的影响下降时, 中性过程作用相对会增强。

尽管本文证明了中性理论模型对极端干旱区 荒漠河岸林物种多度分布预测的有效性, 但不能排 除种间竞争、生态位分化和生境过滤等作用对荒漠 植物多度分布的影响。因此, 初步认为中性随机过 程对荒漠河岸林物种多样性格局形成发挥着主导 作用, 且中性过程与生态位过程共同作用于荒漠植 物群落的构建过程, 二者的贡献随生境变化此消彼 
长。另外, 采用模型拟合物种多度曲线的机理检验 多为弱检验, 多度模型对实际观测数据的拟合效果 良好并不能完全验证机理(Magurran, 2005; Volkov et al, 2005; McGill et al, 2006)。

采用代表不同生态学过程的模型来拟合群落 物种多度分布, 虽然能够描述群落物种多度的组织 结构, 但单纯基于多度分布格局的模型无法验证其 背后的生态学机制。因此, 要明确生态位过程与中 性过程在荒漠河岸林群落构建过程中的作用, 未来 需要将多度曲线与物种空间分布格局、种间关联 性、功能形状、 $\beta$ 多样性、物种面积关系等信息相 结合(May et al, 2015)，整合尺度效应、地形、气候、 土壤等因子进行更深入的多度分布格局分析, 以期 更好地解释荒漠河岸林生物多样性的维持机制。

\section{ORCID}

康佳鹏 (D) https://orcid.org/0000-0002-2659-3735

冯春晖 (iD https://orcid.org/0000-0002-9969-1934

王海珍 (D) https://orcid.org/0000-0002-9945-1025

\section{参考文献}

Bao SD (2000) Analysis of Soil Agrochemistry. China Agriculture Press, Beijing. (in Chinese) [鲍士旦 (2000) 土 壤农化分析. 中国农业出版社, 北京.]

Bulmer MG (1974) On fitting the Poisson lognormal distribution to species-abundance data. Biometrics, 30, 101-110.

Burnham KP, Anderson DR (2002) Model Selection and Multimodel Inference: A Practical Information-Theoretic Approach, 2nd edn. Springer-Verlag, New York.

Chen TG, Zhang JT (1999) A comparison of fifteen species diversity indices. Henan Science, (S1), 62-64, 78. (in Chinese with English abstract) [陈廷贵, 张金屯 (1999) 十 五个物种多样性指数的比较研究. 河南科学, (S1), 62-64, 78.]

Chen YN, Wang Q, Li WH, Ruan X, Chen YP, Zhang LH (2006) Study on rational groundwater level characterization of vegetation physiology and ecology data: Taking ecological restoration process in the lower reaches of Tarim River as an example. Chinese Science Bulletin, 51, 7-13. (in Chinese) [陈亚宁, 王强, 李卫红, 阮晓, 陈亚鹏, 张丽华 (2006) 植被生理生态学数据表征的合理地下水位研究 一以塔里木河下游生态恢复过程为例. 科学通报, 51, 7-13.]

Cheng JJ, Mi XC, Ma KP, Zhang JT (2011) Responses of species-abundance distribution to varying sampling scales in a subtropical broad-leaved forest. Biodiversity Science, 19, 168-177. (in Chinese with English abstract) [程佳佳, 米湘成, 马克平, 张金屯 (2011) 亚热带常绿阔叶林群落
物种多度分布格局对取样尺度的响应. 生物多样性, 19, 168-177.]

Damasceno-Junior GA, Semir J, Dos Santos FAM, Leitão-Filho HF (2005) Structure, distribution of species and inundation in a riparian forest of Rio Paraguai, Pantanal, Brazil. Flora, 200, 119-135.

Fang XF, Yang QS, Liu HM, Ma ZP, Dong S, Cao Y, Yuan MJ, Fei XY, Sun XY, Wang XH (2016) Distribution of species abundance of evergreen and deciduous woody plants in the evergreen broad-leaved forests at Tiantong, Zhejiang. Biodiversity Science, 24, 629-638. (in Chinese with English abstract) [方晓峰, 杨庆松, 刘何铭, 马遵平，董舒，曹烨， 袁铭晈, 费希昒, 孙小颖, 王希华 (2016) 天童常绿阔叶 林中常绿与落叶物种的物种多度分布格局. 生物多样性, 24, 629-638.]

Fisher RA, Corbet AS, Williams CB (1943) The relation between the number of species and the number of individuals in a random sample of an animal population. The Journal of Animal Ecology, 12, 42-58.

Fralish JS, Crooks FB, Chambers JL, Harty FM (1991) Comparison of presettlement, second-growth and old-growth forest on six site types in the Illinois Shawnee hills. American Midland Naturalist, 125, 294-309.

Han L, Chen JL, Wang JQ, Wang HZ, Lü RH, Kang JP (2019) Species composition, community structure, and floristic characteristics of desert riparian forest community along the mainstream of Tarim River. Plant Science Journal, 37, 324-336. (in Chinese with English abstract) [韩路, 陈家力, 王家强, 王海珍, 吕瑞恒，康佳鹏 (2019) 塔河源荒漠河 岸林群落物种组成、结构与植物区系特征. 植物科学学 报, 37, 324-336.]

Han L, Wang HZ, Peng J, Mo ZX (2007) Spatial distribution patterns and dynamics of major population in Populus euphratica forest in upper reaches of Tarim River. Botanica Boreali-Occidentalia Sinica, 27, 1668-1673. (in Chinese with English abstract) [韩路, 王海珍, 彭杰, 莫治新 (2007) 塔里木河上游天然胡杨林种群空间分布格局与动 态研究. 西北植物学报, 27, 1668-1673.]

Han L, Wang JQ, Wang HZ, Niu JL, Yu J (2016) Niche and spatial distribution pattern analysis of the main populations of the Tarim desertoasis ecotone. Plant Science Journal, 34, 352-360. (in Chinese with English abstract) [ 韩路, 王家强, 王海珍, 牛建龙, 于军（2016）塔里木荒漠绿洲过渡带主 要种群生态位与空间格局分析. 植物科学学报, 34, 352-360.]

Hill MO (1973) Diversity and evenness: A unifying notation and its consequences. Ecology, 54, 427-432.

Hubbell SP (2001) The Unified Neutral Theory of Biodiversity and Biogeography. Princeton University Press, Princeton.

Hubbell SP (2005) Neutral theory in community ecology and the hypothesis of functional equivalence. Functional Ecology, 19, 166-172.

Hubbell SP, Foster RB (1986) Commonness and rarity in a 
neotropical forest: Implications for tropical tree conservation. In: Conservation Biology: the Science of Scarcity and Diversity (ed. Soulé ME), pp. 205-231. Sinauer Associates, Inc., Sunderland, MA.

Jiang LM, Lü GH, Gong YM, Li Y, Wang HF, Wu DY (2021) Characteristics and driving mechanisms of species beta diversity in desert plant communities. PLoS ONE, 16, e0245249.

Laurance WF, Ferreira LV, Rankin-de Merona JM, Laurance SG (1998) Rain forest fragmentation and the dynamics of Amazonian tree communities. Ecology, 79, 2032-2040.

Li QD, Liu MX, Xia SJ, Nan XN, Jiang XX (2019) Changes in species-abundance relationships of plant communities with slopes in alpine meadows of Gannan, China. Chinese Journal of Plant Ecology, 43, 418-426. (in Chinese with English abstract) [李全弟, 刘旻霞, 夏素娟, 南笑宁, 蒋晓 轩 (2019) 甘南高寒草甸群落的物种-多度关系沿坡向的 变化. 植物生态学报, 43, 418-426.]

Li X, Zhu WZ, Sun SQ, Shu SM, Sheng ZL, Zhang J, Liu T, Zhang ZC (2020) Influence of habitat on the distribution pattern and diversity of plant community in dry and warm valleys of the middle reaches of the Dadu River, China. Biodiversity Science, 28, 117-127. (in Chinese with English abstract) [李霞, 朱万泽, 孙守琴, 舒树沝, 盛哲良, 张军, 刘亭, 张志才 (2020) 大渡河中游干暖河谷区生境对植 物群落分布格局和多样性的影响. 生物多样性, 28, 117-127.]

Liu JZ, Chen YN, Li WH, Chen YP (2004) Analysis on the distribution and degraded succession of plant communities at lower reaches of Tarim River. Acta Ecologica Sinica, 24, 379-383. (in Chinese with English abstract) [刘加珍, 陈亚 宁, 李卫红, 陈亚鹏 (2004) 塔里木河下游植物群落分布 与衰退演替趋势分析. 生态学报, 24, 379-383.]

Liu MX, Li QD, Jiang XX, Xia SJ, Nan XN, Zhang YY, Li BW (2020) Contribution of rare species to species diversity and species abundance distribution pattern in the Gannan subalpine meadow. Biodiversity Science, 28, 107-116. (in Chinese with English abstract) [刘旻霞, 李全弟, 蒋晓轩, 夏素娟, 南笑宁, 张娅娅, 李博文 (2020) 甘南亚高寒草 甸稀有种对物种多样性和物种多度分布格局的贡献. 生 物多样性, 28, 107-116.]

Liu MX, Liu JJ, Du XG, Zheng XG (2010) Fitting different models to species abundance distribution patterns in three plant communities in sub-alpine meadow. Acta Ecologica Sinica, 30, 6935-6942. (in Chinese with English abstract) [刘梦雪, 刘佳佳, 杜晓光, 郑小刚 (2010) 亚高寒草甸不 同生境植物群落物种多度分布格局的拟合. 生态学报, 30, 6935-6942.]

MacArthur RH (1957) On the relative abundance of bird species. Proceedings of the National Academy of Sciences, USA, 43, 293-295.

Magurran AE (2005) Species abundance distributions: Pattern or process? Functional Ecology, 19, 177-181.
Magurran AE, Henderson PA (2003) Explaining the excess of rare species in natural species abundance distributions. Nature, 422, 714-716.

Matthews TJ, Whittaker RJ (2015) On the species abundance distribution in applied ecology and biodiversity management. Journal of Applied Ecology, 52, 443-454.

May F, Huth A, Wiegand T (2015) Moving beyond abundance distributions: Neutral theory and spatial patterns in a tropical forest. Proceedings of the Royal Society B: Biological Sciences, 282, 20141657.

Mayfield MM, Levine JM (2010) Opposing effects of competitive exclusion on the phylogenetic structure of communities. Ecology Letters, 13, 1085-1093.

McGill BJ, Etienne RS, Gray JS, Alonso D, Anderson MJ, Benecha HK, Dornelas M, Enquist BJ, Green JL, He FL, Hurlbert AH, Magurran AE, Marquet PA, Maurer BA, Ostling A, Soykan CU, Ugland KI, White EP (2007) Species abundance distributions: Moving beyond single prediction theories to integration within an ecological framework. Ecology Letters, 10, 995-1015.

McGill BJ, Maurer BA, Weiser MD (2006) Empirical evaluation of neutral theory. Ecology, 87, 1411-1423.

Motomura I (1932) A statistical treatment of ecological communities. Zoological Magazine, 44, 379-383.

Niu KC, Liu YN, Shen ZH, He FL, Fang JY (2009) Community assembly: The relative importance of neutral theory and niche theory. Biodiversity Science, 17, 579-593. (in Chinese with English abstract) [牛克昌, 刘怿宁, 沈泽 昊, 何芳良, 方精云 (2009) 群落构建的中性理论和生态 位理论. 生物多样性, 17, 579-593.]

Prado PI, Miranda MD, Chalom A (2018) Package 'sads': Maximum Likelihood Models for Species Abundance Distributions. R package version 0.4.2. https:/CRAN.Rproject.org/package=sads/. (accessed on 2020-05-24)

Preston FW (1948) The commonness, and rarity, of species. Ecology, 29, 254-283.

Ren P, Wang XA, Guo H (2009) Species abundance distribution pattern of forest communities on Loess Plateau. Chinese Journal of Ecology, 28, 1449-1455. (in Chinese with English abstract) [任萍, 王孝安, 郭华 (2009) 黄土 高原森林群落物种多度的分布格局. 生态学杂志, 28 , 1449-1455.]

Sattar K, Lü GH, Jiang LM, Wang HF, Wang JL (2020) Responses of species abundance distribution to varying sampling scales in a desert plant community in the Ebinur Lake Basin. Arid Zone Research, 37, 1273-1283. (in Chinese with English abstract) [坤杜孜·萨塔尔, 吕光辉, 蒋腊梅, 王恒方, 王金龙 (2020) 艾比湖荒漠植物物种多 度分布格局的尺度效应. 干旱区研究, 37, 1273-1283.]

Shi JM, Fan CF, Liu Y, Yang QP, Fang K, Fan FL, Yang GY (2015) Species-abundance distribution patterns along succession series of Phyllostachys glauca forest in a limestone mountain. Chinese Journal of Applied Ecology, 
26, 3595-3601. (in Chinese with English abstract) [施建敏, 范承芳, 刘扬, 杨清培, 方楷, 范方礼, 杨光耀 (2015) 石灰岩山地淡竹林演替序列的群落物种多度分布格局. 应用生态学报, 26, 3595-3601.]

Tokeshi M (1993) Species abundance patterns and community structure. Advances in Ecological Research. 24, 111-186.

Ulrich W, Soliveres S, Thomas AD, Dougill AJ, Maestre FT (2016) Environmental correlates of species rank-abundance distributions in global drylands. Perspectives in Plant Ecology, Evolution and Systematics, 20, 56-64.

Volkov I, Banavar JR, He FL, Hubbell SP, Maritan A (2005) Density dependence explains tree species abundance and diversity in tropical forests. Nature, 438, 658-661.

Volkov I, Banavar JR, Hubbell SP, Maritan A (2003) Neutral theory and relative species abundance in ecology. Nature, 424, 1035-1037.

Wang JM, Wang WJ, Li JW, Feng YM, Wu B, Lu Q (2017) Biogeographic patterns and environmental interpretation of plant species richness in desert regions of Northwest China. Biodiversity Science, 25, 1192-1201. (in Chinese with English abstract) [王健铭, 王文娟, 李景文, 冯益明, 吴 波, 卢琦 (2017) 中国西北荒漠区植物物种丰富度分布 格局及其环境解释. 生物多样性, 25, 1192-1201.]

Wang SX, Guo H, Wang XA, Fan WY (2013) Dispersal limitation versus environment filtering in the assembly of plant communities in the Ziwu Mountains. Scientia Agricultura Sinica, 46, 4733-4744. (in Chinese with English abstract) [王世雄, 郭华, 王孝安, 范玮熠 (2013) 扩散限 制和环境笁选对子午岭森林群落构建的相对贡献. 中国 农业科学, 46, 4733-4744.]

Whittaker RH (1965) Dominance and diversity in land plant communities: Numerical relations of species express the importance of competition in community function and evolution. Science, 147, 250-260.

Wu AC, Deng XW, He HL, Ren XL, Jing YR, Xiang WH, Ouyang S, Yan WD, Fang X (2019) Responses of species abundance distribution patterns to spatial scaling in subtropical secondary forests. Ecology and Evolution, 9,
5338-5347.

Wu CZ, Hong W (1997) Study on Weibull model for species abundance distribution of Tsoongiodendron odorum forest. Journal of Fujian College of Forestry, 17, 20-24. (in Chinese with English abstract) [吴承祯, 洪伟 (1997) 观光 木群落物种多度分布的Weibull模型研究. 福建林学院学 报, 17, 20-24.]

Yan Y, Zhang CY, Zhao XH (2012) Species-abundance distribution patterns at different successional stages of conifer and broad-leaved mixed forest communities in Changbai Mountains, China. Chinese Journal of Plant Ecology, 36, 923-934. (in Chinese with English abstract) [闵琰, 张春雨, 赵秀海 (2012) 长白山不同演替阶段针 阔混交林群落物种多度分布格局. 植物生态学报, 36, 923-934.]

Zhang S, Lin F, Yuan ZQ, Kuang X, Jia SH, Wang YY, Suo YY, Fang S, Wang XG, Ye J, Hao ZQ (2015) Herb layer species abundance distribution patterns in different seasons in an old-growth temperate forest in Changbai Mountain, China. Biodiversity Science, 23, 641-648. (in Chinese with English abstract) [张姗, 菌菲, 原作强, 匡旭, 贾仕宏, 王 芸芸, 索炎炎, 房帅, 王绪高, 叶吉, 郝占庆 (2015) 长 白山阔叶红松林草本层物种多度分布格局及其季节动态. 生物多样性, 23, 641-648.]

Zhang XN, Yang XD, Lü GH (2016) Diversity patterns and response mechanisms of desert plants to the soil environment along soil water and salinity gradients. Acta Ecologica Sinica, 36, 3206-3215. (in Chinese with English abstract) [张雪妮, 杨晓东, 吕光辉 (2016) 水盐梯度下荒 漠植物多样性格局及其与土壤环境的关系. 生态学报, 36, 3206-3215.]

Zhou HH, Chen YN, Zhu CG, Li Z, Fang GH, Li YP, Fu AH (2020) Climate change may accelerate the decline of desert riparian forest in the lower Tarim River, Northwestern China: Evidence from tree-rings of Populus euphratica. Ecological Indicators, 111, 105997.

(责任编委: 米湘成 责任编辑: 黄祥忠) 